\title{
The Analysis of the Rhetorical Device-Pun in the Ogura Anthology of One Hundred Tanka-poems
}

\author{
LI Ya-ling \\ College of Literature and Law \\ Sichuan Agricultural University \\ Ya'an ,Shaanxi,625014 China
}

\begin{abstract}
Pun is one of the most important rhetorical devices in Japanese Waka, which not only plays a significant role in creating the poetic conceptualization of implicitness and obscurity, but also is closely related to the Japanese daily thinking mode. "The Ogura Anthology of One Hundred Tanka-poems" is an influential Waka Shu in Japanese history, where the pun from the type, quantity, gender, class shows the significant characteristics of age and the characteristics of the poems themselves.
\end{abstract}

Keywords- the Ogura Anthology of One Hundred Tanka-poems; Waka; Pun

\section{INTRODUCTION}

The Ogura Anthology of One Hundred Tanka-poems is a collection of waka, which was the most widespread and exerted an extremely profound influence in Japan's history. It was compiled by Sadaie Fujiwara (1162-1241) through choosing a masterpiece respectively from the works of 100 singers between the Nara Age and the early Kamakura Age. The songbook was also known as Waka on the Color Papers of Kokura Mountain House or Waka on the Color Papers of towering mountain, because it is was orig inally complied in the towering Kokura mountain house of Kyoto and written on the color papers of the mountain house's paper window. In the Ogura Anthology of One Hundred Tanka-poems, pun is used for expressing the visual angle and aesthetic construction form with its unique perspective of interest and becomes very special in many types of rhetoric ways. In China's academic circles, the study of Japanese waka is still in the stage of introduction and translation, and the deep discussion on the specific rhetoric ways has not been commonly seen and especially the study of the pun used in the works of the Ogura Anthology of One Hundred Tanka-poems with great significance in the development history of waka is still blank. Based on the above analysis, the expressive form of pun and the cultural characteristics reflected from pun used in waka are investigated through analyzing the related works in the Ogura Anthology of One Hundred Tanka-poems, so as to promote the scholars in China's academic circles to understand and discuss the pun as a rhetoric way in waka.

\section{THE CLASSIFICATION OF THE PUB IN WAKA}

Pun is called as hanging words in Japanese and meansthat the composer consciously makes use of the same word and the same sentence in the same context with the help of the characteristics of homonyms when he is composing waka, and it simultaneously possesses two or more meanings, so that the modified part becomes a dual structure. In this way, the picture of things is described superficially, but actually the psychological activities and inner feelings of people are metaphorical.

From the point of $\mathrm{v}$ iew of form, puns in general can be divided into partial correlation and overall correlation. The partial correlation means that a double meaning is available for a word.

In addition, puns in waka can also be divided into "dual-purpose puns" and "chain puns" in terms of the contextual connection way. "Dual-purpose" means a word is connected with the preliminaries and possesses the meanings of two words, and also constitutes a dual meaning.

In contrast, there is different echo in the context of "chain pun", and pun plays a connecting effect like chains in the statements [2].

\section{THE RHETORICEFFECT OF PUNSIN WAKA}

First, the semantic pun can enrich the emotional meanings in waka and help create an under-meaning, hazy artistic conception of poetry. The polysemy of Japanese words pro motes the readers to produce lu xuriant associations when reading the same word and the same sentence, so that different semantic understanding and emotional experience are obtained. A certain amount of ambiguity and communication error may be caused in the daily communication. However, the beauty of implicitness is always in Japanese waka, and the ambiguity in the sense of a word won't destroy the artistic style of poetry, and also will multiply the intensions of waka, so that the mixed beauty of implicitness is created.

Second, the multiple images of poem are produced by semantic puns, making the deep temperament and interest harmoniously integrated with the superficial images. Words are static and independent, and it is very difficult to express the temperament and interest through the 
establishment of image by words, but not relying on logic correlative words. Thus, pun embodies its powerful characteristics and makes the image of a poem overlapped and dense. As Mr. Wiser says, "The readers are reading between texts based on a nomadic perspective" [3]. Puns not only make the sentences more fluent and the images more prominent, but also promote the readers to naturally feel the personal feelings expressed by waka composers in the multiple-structural image.

Third, the semantic puns can help create a reasoning language style with implicative and thought-provoking meanings. The way of ambiguity and implication was mostly applied by Japanese, while the puns with polysemy were often used by the ancient singers to directly express their own opinions, so that an implicit language expressive style was created.

\section{THE UNIQUE EXPRESSIVE MENTALITY OF THE PUNS} IN WAKA

Wang Guowei said, in Human Words, mentions the relationship between "isolation" and "non-isolation" in poems, and thinks the poems with "non-isolation" are the excellent works. The "isolation" discussed in this paper is standardized by "whether words are happening at present", and it is also known as "non-isolation", but not the real "isolation". The "isolation" and "non-isolation" is a problem of "hidden" and "apparent" in terms of the artistic expression. ZHU Guangqian, in the "Hidden" and "Apparent" of Poems, points out that the scenery poems should be apparent, while the love poems should be hidden [4]. In puns, the "apparent" in the scenery poems and the "hidden" in the love poems are connected, in order to achieve the effect of fused feelings and natural setting and the profoundly meaningful realm [5].

After the puns in the Ogura Anthology of One Hundred Tanka-poems are analyzed, it is found that waka is not only "isolated" and also there are many layers isolated in it, but the feelings conveyed by it are profound. The "isolation" is not only an expressive way in poetic art, but also an extension of Japanese unique way of thinking in waka. Therefore, it is known that pun, as a microcosm of the typical Japanese box-setting culture, is isolated layer upon layer, in which infinite abundance is overlapped and carried in the limited space through the "boundary-association" relationship. The so-called "boundary" is to highlight some connection, but not to cover something. This is just like that people can isolate two rooms with a piece of cloth, but without wall in daily life, to set up a "boundary" and also highlight the link between the two spaces through the "boundary" [6].

V. 4. THE REPRESENT ATIVENESS OF THE PUNS IN THE OGURA ANTHOLOGY OF ONE HUNDRED TANKA-POEMS

The Ogura Anthology of One Hundred Tanka-poems is very widely popular, and has become the primary text for the people in the world to learn waka. Its position in the development history of Japanese poetry can be comparable to the Three Hundred Tang Poems of China. The song collection involves the remote ages, the mediaeval age, and the Kamakura age; 100 singers were chosen from the tremendous amount of legends, and also one masterpiece was selected respectively from these 100 singers. In the one hundred waka, puns are used in 27 of them representing the classic pun types of 10 songbooks such as the Collection of the Ancient and modern Waka Works and the Gosen Wakash, and many of them have become the models for the waka creation of the later generations.

From the types, all-purpose puns are more than chain puns in the Ogura Anthology of One Hundred Tankapoems, and the coexisting puns in all-purpose puns are more than responding puns. Coexisting pun can make a waka possess two contexts, and the deep temperament and interest and superficial image of waka are in harmonious coexistence, and thus it is the most skillful and artistic type in puns [7]. In the songbook, all types of pun skills are contained basically, and also coexisting puns occupy nearly half of the proportion and reflect the highest application level of puns in the kamakura age, so that the Ogura Anthology of One Hundred Tanka-poems becomes an important milestone of pun skills forms. From the perspective of a pun in position and the waka in which puns are used, the puns in more than half of the waka appeared in the fourth sentence, followed by the second sentence, the third sentence, and the fifth sentence in turn. The use of pun in the first sentence is the rarest. In waka, the position of the puns is where "song eye" is located and also the key to start the whole song. In the Manyo Age, Manyo waka giving top priority to "tones 5 and 7" was simple and powerful, and came straight to the point, in which the use of makurakotoba was more developed. In the Collection of the Ancient and modern Waka Works and the New Collection of the Ancient and modern Waka Works ages, waka themes giving top priority to "tones 5 and 7" gradually moved backward, and pun accordingly developed in the middle and later parts of waka. The song style with its theme put at the end can is easy to create a mysterious gorgeous, faint, and artistic conception, in order to refine and play the maneuvering beauty of waka's profound meanings [8].

In addition, puns appear in all types of waka such as love songs, four-seas on songs, miscellaneous songs, and parting songs, but nearly half of puns are in love songs, followed by miscellaneous songs, four-seas on songs, and parting songs in turn. Also, 18 singers among the total 79 male singers made use of puns, and puns were in 7 love songs, 5 four-season songs, 5 miscellaneous songs, and 1 parting song; 9 singers among the total 21 female signers used puns, and puns were in 5 love songs. On the whole, men using puns in the Ogura Anthology of One Hundred Tanka-poems were more than women, but the promotion of female singers was higher than that of male singers. 
This also gives a reflection to that puns are more propitious to create hazy, implicit images from another aspect, so that the love not to be directly described in the mind is transferred, and also the female singers' preferences and habitual practice for puns are promoted in the love song creation. This also really reflects the integral style of the Ogura Anthology of One Hundred Tanka-poems in which pure, fresh, bright, and beautiful love songs are used as the main themes. This style was perfectly blended together with the ethereal, desolate, and distant aesthetic ideas praised highly in the Kamakura Age. Through the pun as a distinctive rhetorical form, the partly hidden and partly visible, hazy and indirect emotional artistic conception and lasting appeal of man and woman are well reflected in the words of waka [9].

Certainly, pun is used in the poems of many nations in the world, and the result of human's rethinking of sounds and meanings is directly applied to the eternal poetic languages, from which the consistency of human thinking with the feeling way is manifested. However, pun was very frequently used in the Ogura Anthology of One Hundred Tanka-poems, and the use techniques were clever and implicative, making the unique Japanese aesthetic view of Japanese reflected undoubtedly. From this point, it is still an important subject to further explore the inner feeling expression and aesthetic interest of Japanese based on pun in waka in the future.

\section{REFERENCES}

[1] Tanaka Zhongchu, Tanaka Zhiri. Ogura Hyakunin Isshu [M]. Tokyo: Wutong Academy, 1982.

[2] Tada Michitaro. Translated by Wang Liying. Japanese Culture around Us [M]. Nanjing: Nanjing University Press, 2008.

[3] Jiang Mawu, Gu Shanmao, Zhuyue Jianer. An Introduction to Revised National Language [M]. Kyoto: Kyoto Academy, 2008.

[4] Wu Deqing. Appreciation on the Ogura Anthology of One Hundred Tanka-poems [M]. Wuhan: Wuhan University of Science and Technology Press, 2008.

[5] Enhua PENG. The History of Japanese Waka [M]. Shanghai: Shanghai Stanford University Press, 1986.

[6] SHI Yidui. Notes to Human Words [M]. Hunan: Yuelu Press, 2003.

[7] Gao Wenhan. Japanese Waka Rhetorical Skills: Centered at Paronomasia and "Predestination" [J]. People's Liberation Army Foreign Language School, 2009, (32):113-116.

[8] Qiu Shijun. Japanese Waka Rules and Skills [J]. Journal of Shanghai International Studies University, 1985, (37):57-62.

[9] Zhao Qing. An Investigation on the Structure of Japanese-Chinese Poetry [J]. Language and Culture, 2007:53-68. 